\title{
Huella minera en la ciudad de Guanajuato (México) entre los siglos XVI-XIX: morfología urbana y planimetría en el archivo de Indias en Sevilla (España)
}

\author{
Mining trace in the city of Guanajuato (México) between the XVI-XIX centuries: \\ urban morphology and planimetry in the archive of Indias in Sevilla (Spain)
}

Recibido: mayo 2020

Aceptado: septiembre 2020

\section{Resumen}

Guanajuato es una ciudad singular: su localización, paisaje único e historia han condicionado la morfología urbano-territorial de la ciudad y su entorno, evolucionando ambos junto a la minería y generando una interesante bibliografía y planimetría. Constituida por un centro histórico no muy longevo y una serie de asentamientos periféricos producto de la actividad minera, en Julio de 1982 la ciudad es declarada Zona de Monumentos Históricos por el Instituto de Antropología e Historia, en 1988 fue inscrita por la UNESCO en la Lista de Patrimonio Mundial bajo el nombre de Ciudad Histórica de Guanajuato y Minas Adyacentes, y desde 2006 tiene el reconocimiento de ser la Quinta Ciudad más Bella del Mundo, y todo ello gracias a su arquitectura y minería como recuerdo de su pasado colonial. El interés de este artículo radica en realizar un acercamiento a los elementos que han dejado su propia huella como consecuencia de la actividad minera, y referenciarlo a los planos que se encuentran localizados en el Archivo de Indias de Sevilla.

\section{Palabras Clave:}

Ciudad minera; haciendas beneficio; bocetos históricos

\author{
Nieves Martínez-Roldán ${ }^{1}$ \\ Lola Goytia-Goyenechea ${ }^{2}$
}

\begin{abstract}
Guanajuato is a singular city: its location, unique landscape and history have conditioned the urban-territorial morphology of the city and its environment, evolving both alongside mining and generating an interesting bibliography and planimetry. Constituted by a not very longlived historical center and a series of peripheral settlements, product of the mining activity, in July 1982 the city is declared Historic Monuments Zone by the Institute of Anthropology and History. In 1988 it was inscribed by UNESCO on the World Heritage List under the name of Historic City of Guanajuato and Adjacent Mines, and since 2006 it has been recognized as the fifth most beautiful city in the world, all thanks to its architecture and mining as a reminder of its colonial past. The interest of this article is to make an approach to the elements that have left their own trace, as a result of the mining activity, and to refer it to the plans that are located in the Archive of the Indies of Sevilla.
\end{abstract}

\section{Keywords:}

Mining town; profit farm; historical sketches

\footnotetext{
1 Nacionalidad: española; adscripción: Escuela Técnica Superior de Arquitectura, Departamento de Urbanística y ordenación del Territorio, Universidad de Sevilla, España; Doctora Arquitecta Urbanista; e-mail: nmr@us.es

2 Nacionalidad: española; adscripción: Escuela Técnica Superior de Arquitectura, Departamento de Urbanística y ordenación del Territorio, Universidad de Sevilla, España; Doctora Arquitecta Urbanista; e-mail: goytia@us.es
} 


\section{TERRITORIO Y CIUDAD MINERA DE GUANAJUATO}

La ciudad de Guanajuato está localizada en las estribaciones de la Sierra del mismo nombre y ocupa una estrecha cañada de 12 kilómetros de longitud. Actualmente pertenece al estado que lleva su nombre, junto a otros 45 municipios más, y por su orografía (Sierra Madre Occidental, Eje Transversal Volcánico y Sierra Madre Oriental) es un lugar idóneo por la riqueza mineral natural de su suelo, destacando el distrito minero de Guanajuato (Sierra Central y Altiplanicie Norte) y su Veta Madre. Ambas circunstancias han generado una intensa actividad extractiva durante cuatrocientos años (Blanco-Parra-Ruiz, 2016, $\mathrm{s} / \mathrm{p}$ ). Los orígenes de esta ciudad coinciden con la caída de Tenochtitlan en 1521, el inicio de la conquista española y sus primeros asentamientos de carácter militar y temporal. En el territorio de Guanajuato destacan las expediciones del español Antonio de Carvajal en 1523 y su encuentro con chichimecas, grupos dedicados a la agricultura y caza, dentro de los cuales conviven otomíes, purépachas (Dávila, 2007, pp 41-46), además de pames, jonaces, guamares y guachiles (Zamora, 2004, pp 25-44), habitantes de los asentamientos preexistentes.

En 1526 los misioneros franciscanos fundan la primera ciudad en el estado de Guanajuato, San Francisco de Acámbaro, mientras en el territorio se distinguen asentamientos mineros que explotan en superficie. En 1537 el virrey Antonio de Mendoza aprueba las Ordenanzas reguladoras de la actividad minera en beneficio de la Real Hacienda, y en 1541 cede las tierras a Rodrigo Vázquez quien castellaniza su legado (Quanaxhuato por Guanajuato) reconociéndose en el año 1546 el verdadero primer asentamiento de Guanajuato-ciudad (Ruiz, 2012, pp 92-126). Hasta el descubrimiento de la plata en las minas de Zacatecas en 1546 y en San Bernabé - San Juan de Rayas en 1548, México como territorio tiene poco que ofrecer (Brading, 2015, s/p), pero tras los descubrimientos los españoles comienzan con la actividad minera a pesar de contar con grandes deficiencias: falta de alojamientos, escasez de comida y casi nula mano de obra son los causantes de hostilidades que son resueltas con las armas (Blanco, Parra, Ruiz, 2016, s/p). Desde 1550 Guanajuato es uno de los principales asentamientos de Nueva España quedando fundado oficialmente en 1554 con el nombre de Real de Minas de Santa Fe. Ya en 1557 se contabilizan 40 compañías mineras en las proximidades de Guanajuato (BlancoParra-Ruiz, 2016, s/p) que irán en aumento tras el descubrimiento de la denominada Veta Madre en 1558. Los jesuitas presentes desde 1574 en el real de Guanajuato-Zacatecas (Blanco-Parra-Ruiz, $2016, \mathrm{~s} / \mathrm{p}$ ) se dedican a la agricultura para alimentar a 4.606 individuos libres y 2.641 individuos forzados de etnia india y negra (Brading, 2015, s/p). Estos trabajadores provienen de Comanja, Arantza, Santa Clara, Chilchota, Uruapan, Pátzcuaro y Cuitzeo entre otros asentamientos (Blanco-ParraRuiz, 2016, s/p).

En 1619 el rey Felipe III la nombra Villa de Santa Fe de Guanajuato y tal es su importancia que, a pesar de la carencia de documentos, se tiene constancia de que en 1632 se envían desde España dos tercios del mercurio obtenido en las Minas de Almadén (Brading, 2015, s/p). Sin embargo, si se conoce que en 1633 habitan 5.000 personas en las zonas mineras, siendo 300 españoles, y que a final de siglo hay un total de 16.000 habitantes repartidos entre el núcleo urbano y los asentamientos dispersos. Así durante este siglo XVII las minas activas son numerosas, destacando Rayas, Mellado, Sirena y Cata, y se contabilizan 47 haciendas de beneficio en las cuales trabajan por obligación un mínimo del $4 \%$ de individuos de cada asentamiento (Blanco-Parra-Ruiz, 2016, s/p) - (Brading, $2015, \mathrm{~s} / \mathrm{p})$. No obstante, y a pesar del éxito de Guanajuato, es un momento de crisis económica general en Nueva España y muchas familias y hacendados se arruinan cambiando de actividad: pasan de la minería a la siembra de cereales y caña de azúcar, y los menos a la cría de ganado (Brading, 2015, s/p).

En 1741 el rey Felipe V nombra a la Villa de Guanajuato, la Muy Noble y Muy Leal Ciudad de Santa Fe de Guanajuato en reconocimiento a las riquezas proporcionadas a la Corona, siendo las minas de Mellado, Cata y Sirena explotadas en superficie y Rayas en profundidad. La subida de impuestos a los mineros por parte de la Corona y las condiciones físicas en que se encuentran los tajos mineros, con escorias interfiriendo los cauces naturales de agua y provocando inundaciones constantes en las zonas residenciales y excavaciones mineras, dan lugar a desacuerdos sociales provocando las rebeliones de 1766 y 1767 en los distritos mineros de Guanajuato y la 
huida hacia las montañas en búsqueda de un lugar seguro (Villalba, 2013, p 37). La solución de la Corona: realizar un nuevo empadronamiento, ya que la población minera cuenta con 40.000 individuos (sólo el diez por ciento vive en el núcleo urbano), y un reparto equitativo entre trabajadores y haciendas de beneficio con la creación del gremio de mineros para defender sus propios intereses mediante unas ordenanzas conjuntas (Brading, 2015, s/p). A partir de 1768 y gracias al descubrimiento de la mina Valenciana (localizada entre Mellado y Rayas), la ciudad de Guanajuato se convierte en la más floreciente de Nueva España (BlancoParra-Ruiz, 2016, s/p): en 1773 existen 175 minas en Guanajuato sin contar los zanguerros explotados, según la Real Hacienda y Caja de Guanajuato, por el propietario y 3 o 4 operarios.

En 1780 se estima que la ciudad cuenta con 50 grandes haciendas de beneficio y 300 casetones de menor tamaño (Brading, 2015, $\mathrm{s} / \mathrm{p})$. Convertida Guanajuato en capital de una de las doce provincias de México desde 1786, cuenta con una población que representa el 10\% de la población total de Nueva España, es más, de los cinco títulos nobiliarios que Carlos III otorga a Guanajuato tres se destinan a personas relacionadas con La Valenciana (Manso, 2008, pp 537-589). A finales de este siglo XVIII, según el censo de 1792, los mineros en Guanajuato llegan a 6.000 personas, y en las numerosas haciendas de beneficio se contabilizan 1.896 arrastres para la molienda del mineral y 14.618 caballos para el tiro de malacates; incluso algunos mineros adquieren tierras en propiedad, llegándose a registrar 421 haciendas mixtas y 899 ranchos. Los trabajadores de las minas están representados por un $42 \%$ de indios, $22 \%$ de mulatos, $1,4 \%$ de mulatosesclavos, $19 \%$ de mestizos, $11 \%$ de españoles y un $3 \%$ de procedencia desconocida (Villalba, 2013, pp 53-83). Además de la minería existen otras actividades tales como comercio, ropa, alimentos, servidumbre, transporte, agricultura, trabajadores del metal y madera, combustibles, escribientes, espectáculos, funcionarios y otros (Brading, 2015, s/p). A principios del siglo XIX en el trabajo subterráneo se contabilizan 1.300 personas dedicadas al transporte y molienda, y en el trabajo en superficie 5.000 personas dedicadas a la fundición y amalgamación.

En 1803 la Real Hacienda reconoce 75 haciendas de beneficio y 200 zangarreros con
1.866 arrastres para la molienda (Brading, 2015, $\mathrm{s} / \mathrm{p}$ ), pero el inicio en 1810 de la Guerra de la Independencia de México produce retrocesos económicos y descensos en la actividad minera pasando de los 90.000 habitantes en 1810 a sólo 6.000 tras los cerca de diez años de guerra. No obstante en 1825 dos empresas inglesas se hacen con la extracción de mineral, la Anglo-Mexican Mining Association y la United Mexican Mining Company, aunque los problemas en desaguar los tajos por el abandono durante la guerra, la imposibilidad de comunicar para consultas técnicas, la falta de trabajadores cualificados, la desconfianza en general hacia el minero mexicano o la falta de adaptación de patronos-trabajadores, a lo que se suma que los ingleses sólo pueden ser arrendatarios y nunca propietarios, hacen que abandonen dicha empresa (Staples, 2018, pp 79-102). Entre 1885-1910 justo hasta el momento de iniciarse la Revolución Mexicana, la ciudad vuelve a renacer industrialmente y en 1892 comienzan a operar empresas mineras norteamericanas: Guanajuato Reduction and Mines, Guanajuato Cons. Mining and Milling, Guanajuato Amalgamated Gold Mines y Guanajuato Development (Uribe, 2001, p 280) potenciando el ferrocarril y facilitando el transporte del mineral de manera más efectiva. Sin embargo, la inestabilidad en el precio de la plata frente al ascenso en su producción obliga a que en 1907 se paralicen 1.108 minas de las 1.235 que hay en actividad en todo el territorio mexicano ocasionando problemas de inactividad importantes (Uribe, 2001, pp 281-297).

Investigadores afirman que las minas de Guanajuato, y en general la minería mexicana, tienen un desarrollo cíclico donde cada 20-30 años las minas se trabajaban y abandonaban por falta de recursos minerales hasta mejorar las condiciones de extracción y de los trabajadores (Antúnez, 1964, p 588). Este fenómeno propicia que la explotación se haya extendido por varios siglos y que los asentamientos se vean sometidas a continuos cambios en su localización (Hausberger, 2009, pp 32-74). A pesar de todo las grandes empresas sobreviven frente a las familiares pero ya con una imagen y un paisaje muy diferente al de los siglos XVI, XVII y XVIII, dejando de ser hitos en el territorio frente a simples instalaciones industriales. 


\section{LA PLANIMETRÍA DEL ARCHIVO DE INDIAS: GUANAJUATO}

La planimetría guardada en el Archivo de Indias es una colección principalmente de planos mineros ubicados entre 1701 y 1786. Entre ellos se encuentra archivado el plano titulado "La Noble Ciudad de Guanajuato. Vista desde lo alto del Cerro de San Miguel por el Poniente" (fig.01) fechado en 1701 y autor desconocido. En él se representan iglesias, conventos, hospitales, casas reales y la alhóndiga pública, y aparecen referenciadas las minas Valenciana, Mellado, Rayas y Serena.

Figura 01. Plano de la ciudad de Guanajuato (1701)

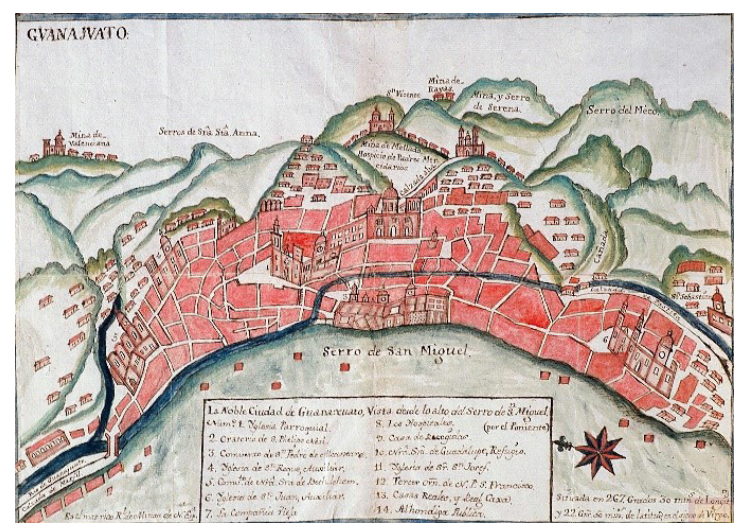

Fuente: Autor desconocido. Archivo General de Indias-Sevilla. Referencia: MP-México, 601

Datos curiosos son que a pesar de su fecha y estar la Mina La Valenciana en auge a partir de 1768, ya ésta aparece representada como si fuese un poblado. La inscripción que aparece en el ángulo inferior izquierdo del plano relata: "Es el más rico Real de Minas de Nueva España", y en el ángulo inferior derecho: "Situada a 267 grados 30 minutos de longitud y 22 grados 50 minutos de latitud en el signo de Virgo".

De 1704 se encuentran archivados dos planos referentes a la Mina de Rayas en Guanajuato ambos realizadas por José de Ledesma. El primero de ellos titulado "Diseño camino interior de la mina de Rayas" (fig.02) representa, con escala gráfica, el camino entre los diferentes socavones y cómo los mineros están realizando sus labores con el torso aparentemente desnudo y chambergo, o cargan el mineral, con aspecto encorvado, en bolsas probablemente de cuero y en animales de tiro, disponiendo para ello de escaleras marinas.
Al pie del plano figura la siguiente inscripción: "Tiene calado esta mina al echado de la vera línea tierra 3 o 6 varas. $Y$ de andadura tiene el camino por donde vayan las mulas desde la boca hasta los cargaderos 820 varas. Y del todo él se ha hecho ahora nuevamente por el Sr Bracamonte desde el número 12 para abajo, que son $45 \mathrm{y}$ se ha laborado en su tiempo desde el número 39", y en la esquina superior derecha aparecen nombrados y numerados los caminos de acceso a lugares secundarios.

Figura 02. Diseño camino interior de la Mina de Rayas en Guanajuato (1704)

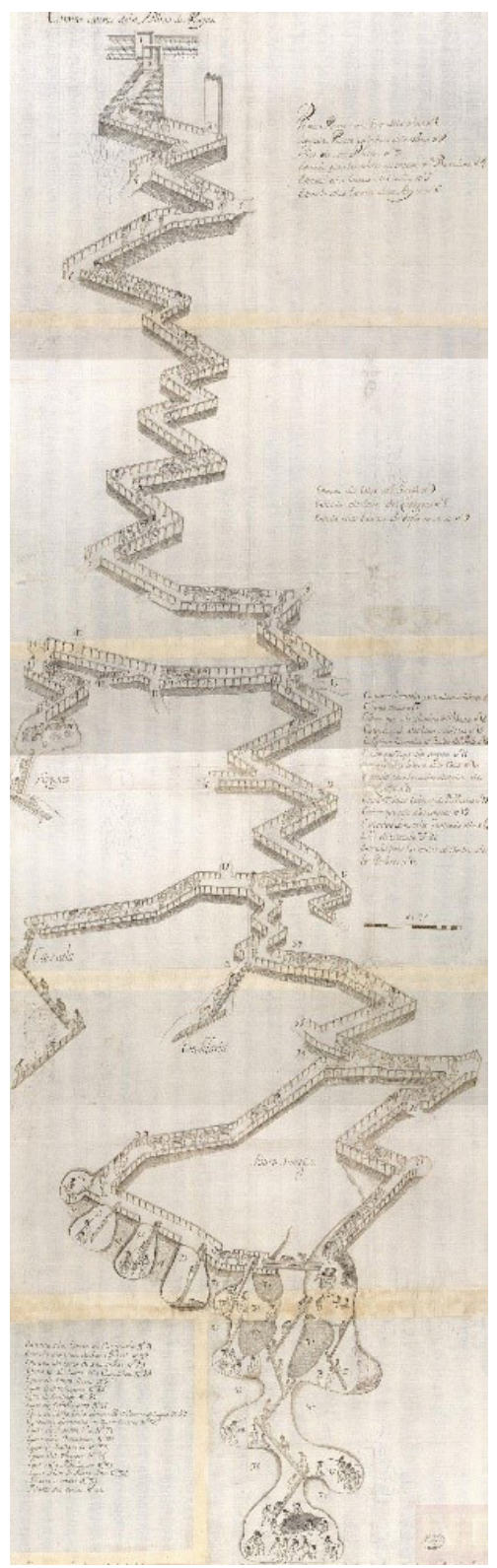

Fuente: Autor, José de Ledesma. Archivo General de Indias-Sevilla. Referencia: MP-México, 97 
Figura 03. Diseño obras y norias para el desagüe de la Mina de Rayas (1704)

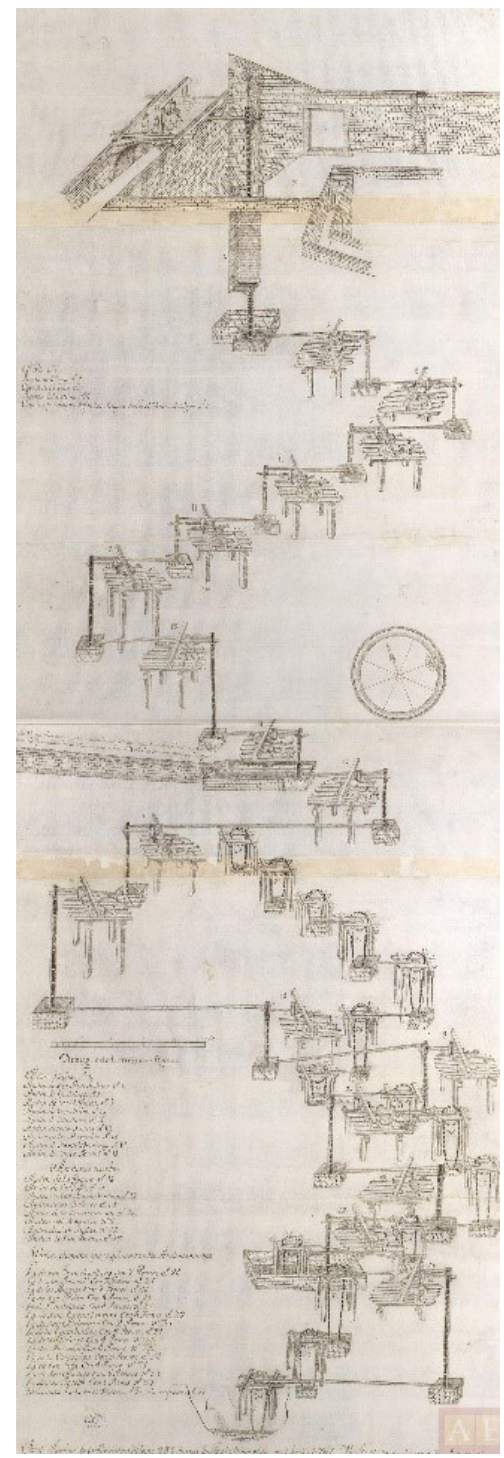

Fuente: Autor, José de Ledesma. Archivo General de Indias-Sevilla. Referencia: MP-México, 96

En el segundo de los planos, también del mismo autor y titulado "Diseño obras y norias para el desagüe de la mina de Rayas", (fig.03) se representan las obras y norias para el desagüe de la mina de Rayas a través de un sistema de bombeo manual con pozos y norias movidas por animales de tiro. Los mineros se representan con la misma fisonomía que en el plano de la figura 02. $\mathrm{Al}$ pie del plano se puede leer: "Tiene esta mina de profundidad a plomo 235 varas hasta el último plano, y al echado 306. Hasta el venero del agua 200. Varas a plomo como aquí se demuestra por su pitipié y al echado 264”. En el lateral izquierdo aparecen varios textos referenciados respecto a los dibujos y en el derecho la orientación. De 1473 está archivado el plano titulado "Medidas ejecutadas según las reales ordenanzas de la mina de Santa Ana" (fig.04), aunque está fechado en 1747 por los archiveros.

Figura 04. Medidas ejecutadas según Reales ordenanzas de la mina de Santa Ana, Real de Guanajuato (1743)

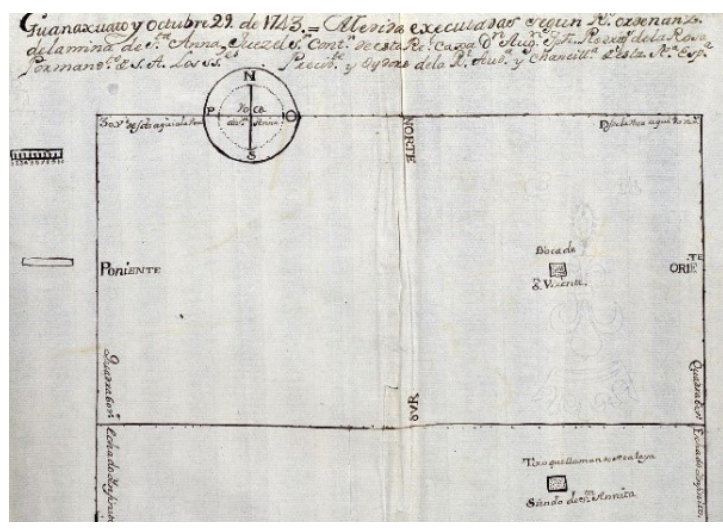

Fuente: Autor desconocido. Archivo General de Indias-Sevilla. Referencia: MP-México, 107

En él se localiza la boca de Santa Ana y de San Vicente, e igualmente hace referencia y localiza el tiro de la Atalaya formando parte de la mina de Santa Anita. El plano marca un recinto donde se establece una profundidad de 60,8 cuadras y a partir de este punto indica "Echado infinito".

De 1747 existe un Mapa (Referencia MPMinas-106) de la mina nombrada San Lucas que forma parte del expediente de demanda del Conde de San Pedro contra Don Francisco Antonio de Estrada, en el que se recogen las pertenencias de la misma con testimonio de Manuel Gómez Corbán y Alonso Cid Fernández.

El plano titulado "Minas de Santa Anita y San Lucas con sus bocas, labores, pertenencias, medidas, con indicación del hilo y echado de las vetas en el cerro de Atalaya, así como de las labores del socavón" (fig. 05) está fechado en 1747. En el lateral izquierdo se describe cada una de las partes de la mina numeradas con letras. En el plano se representan las excavaciones de la mina, y a izquierda y derecha hay sendas representaciones del sol. El plano de 1748 titulado "Gráficos de los cerros de la Atalaya y Rayas y Mellado en el real de Guanajuato" (fig.06) está dividido en dos partes, explicando en el lateral derecho cada superficie del mapa. En el dibujo 
superior se lee: "Mapa fielmente arreglado a la pretensión de Don Francisco de Albarado según las medidas que pide en Santa Anita, suponiendo que todas las minas que contienen se midieran por la misma regla".

Figura 05. Mapa de las minas de Santa Anita y San Lucas con sus bocas, labores, pertenencias, medidas, con indicación del hilo y echado de las vetas en el cerro de Atalaya, así como de las labores del socavón (1747)

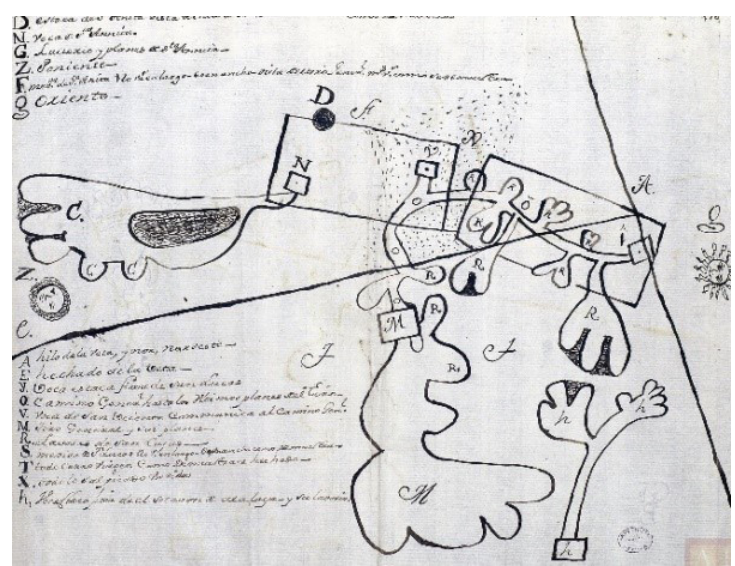

Fuente: Autor desconocido. Archivo General de Indias-Sevilla. Referencia: MP-México, 106

Figura 06. Dos gráficos de los cerros de la Atalaya y Rayas y Mellado en el Real de Guanajuato (1748)

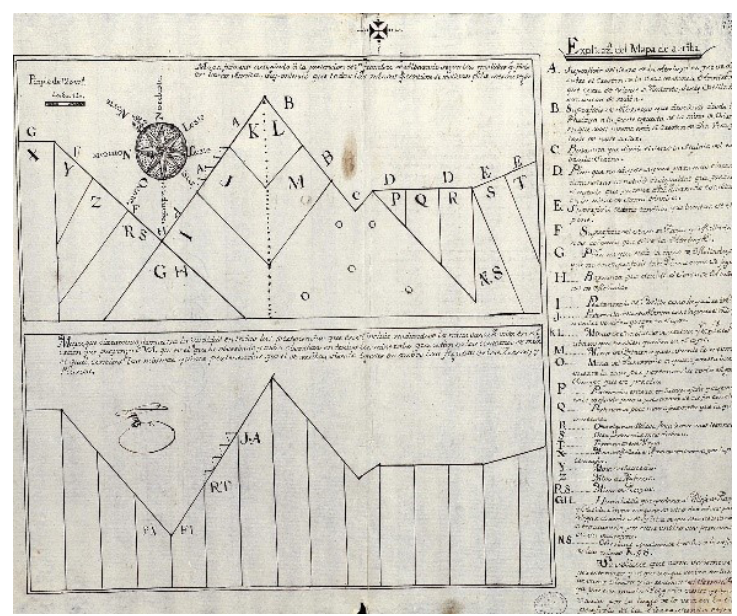

Fuente: Autor desconocido. Encargado por José de la Borda. Archivo General de Indias-Sevilla.

Referencia: MP-México, 97

En el inferior indica: "Mapa que claramente demuestra la igualdad en todas las pertenencias que en si incluye, midiendo la mina Santa Anita en el orden que propongo a Vuestra Alteza que es el que he observado y observan en otros minerales que están en los contornos de México, el cual, contiene las mismas quince pertenencias que el de arriba, siendo iguales en ambos las figuras de los - y Planes".

A todo ello se añade una rosa de los vientos, la escala gráfica (pitipié) en varas, limitándola a 120 varas, y en el borde superior hay dibujada una cruz templaria.

Del año 1749 hay archivado un plano titulado "Mapa de las cinco minas de Rayas, Catilla, Santa Anita, San Lucas de Abajo y San Lucas de Arriba" (fig.07) con la representación de dichas minas. Es un hermoso plano a color con ornamento de hojas, flores y pájaros, una cruz cristiana y corona real en su borde superior y en la inferior una rosa de los vientos con sumo detalle y colorido. En el centro del dibujo ambas inscripciones: "Campo que divide las minas de Rayas y Catilla y de Santa Anita que se haya macizo y con la veta entera" y "Campo o macizo que divide a Santa Anita de San Lucas en lo alto donde está la Veta Virgen". En el ángulo superior izquierdo aparece una tabla referencia para la lectura del plano, y en el lateral derecho la rúbrica del escribano Juan José de Zarazúa con firma en 1749 que indica que el mapa refleja fielmente la copia del delineado geométrico.

Figura 07. Mapa de las cinco minas de Rayas, Catilla, Santa Anita, San Lucas de Abajo y San Lucas de Arriba (1749)

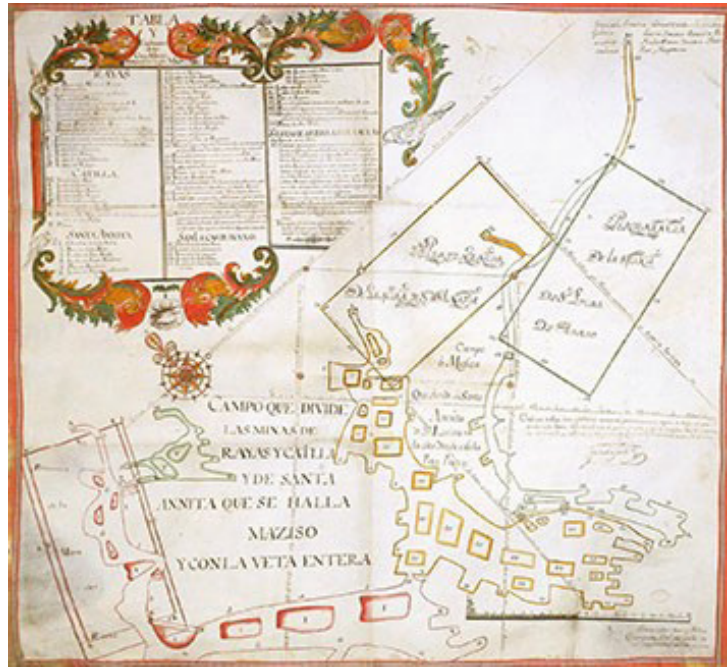

Fuente: Autor, copia realizada por José de Zarazúa. Archivo General de Indias-Sevilla.

Referencia: MP-México, 104

Del mismo año está archivada la planimetría titulada "Medición y localización de la Mina de Santa Anita" (fig.08), también certificada por el 
escribano Juan José de Zarazúa. En este caso el plano a pesar de que en apariencia aporta pocos datos, los que hay son de interés: señala el camino al "pueblo de Azogues" al que se parte por una ladera, las quebradas, el cerro en el que está la mina, las labores, y bocas para "dar la luz y refrescar el ambiente en las minas" entre otros.

Figura 08. Medición y localización de la mina de Santa Anita en el Real de Guanajuato (1749)

Hojas 1 - 2 (abajo) - 3 (derecha)
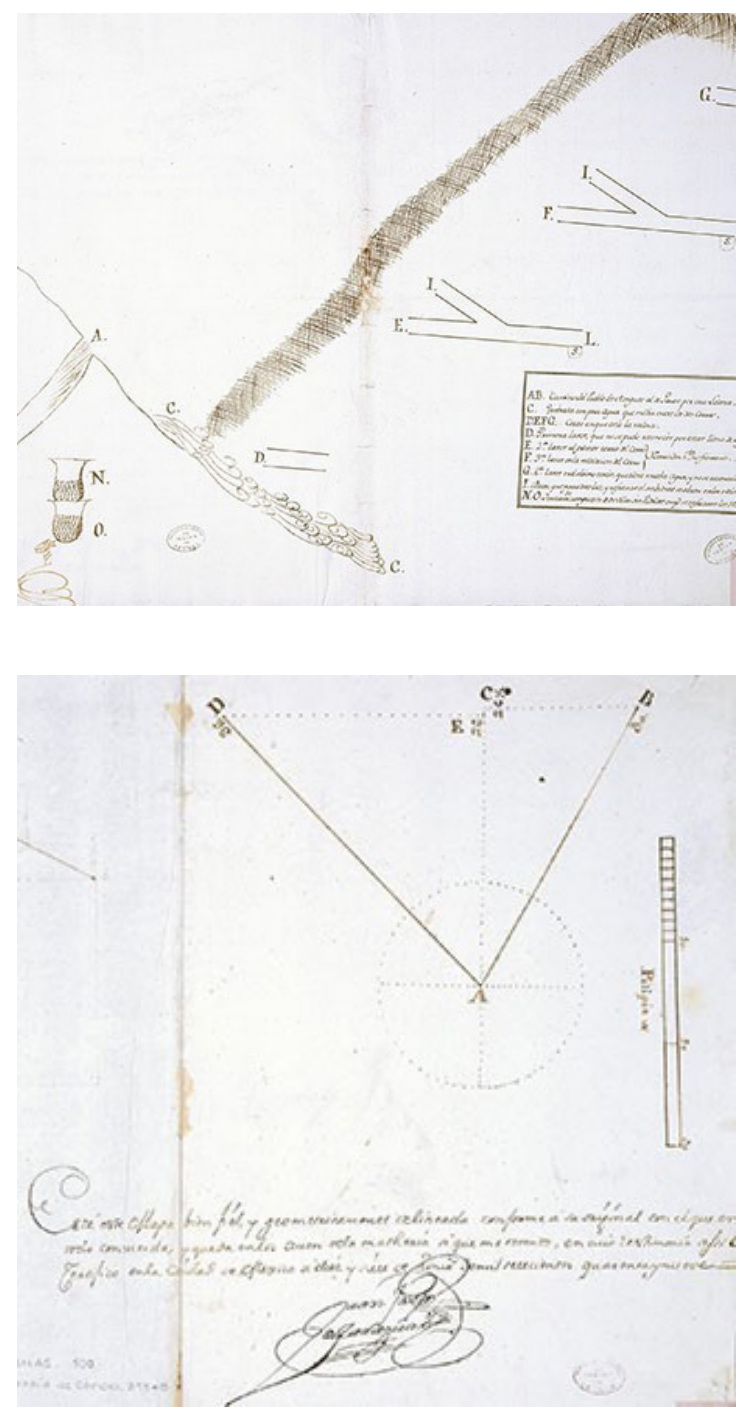

Fuente: Autor desconocido. Archivo General de Indias-Sevilla. Referencia: MP-México, 100

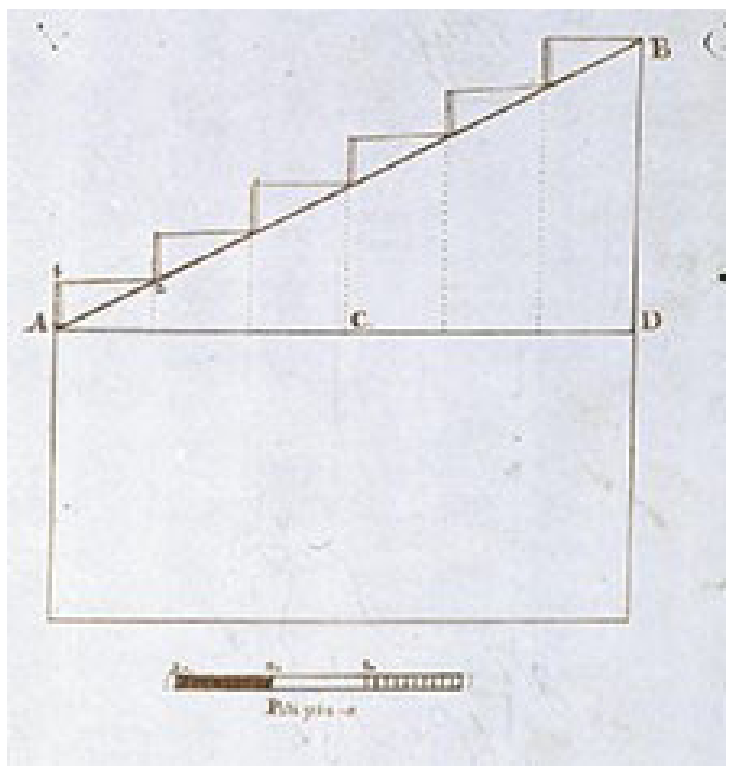

Fuente: Autor desconocido. Archivo General de Indias-Sevilla. Referencia: MP-México, 100

Los últimos tres planos son de 1749. El plano "Del socavón y de San Lucas de Abajo" (fig.09), representa dos cuadras con distancias y medidas, incluye referencias con letras para la lectura del mismo, y en el lateral izquierdo la rúbrica del escribano Juan José de Zarazúa con firma en 1749 , lo que indica que el mapa refleja fielmente la copia del delineado geométrico.

Figura 09. Socavón y de San Lucas de abajo del Real de Guanajuato (1749)

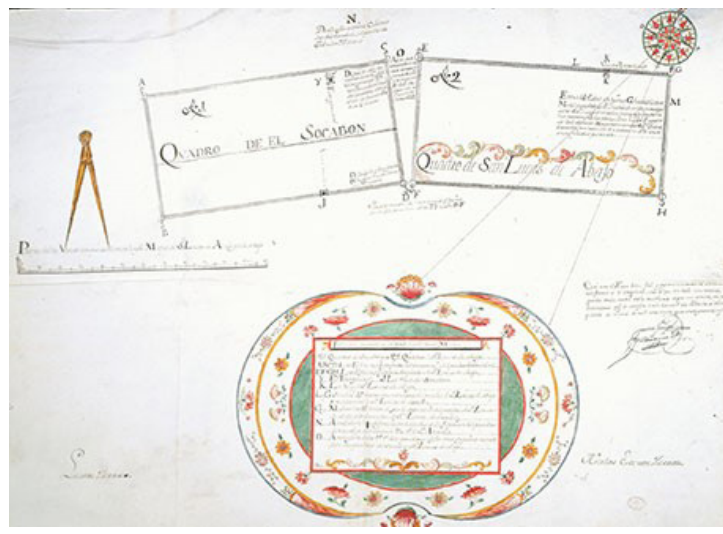

Fuente: Autores, Lázaro Zerrato y Nicolás Zerrato. Archivo General de Indias-Sevilla.

Referencia: MP-México, 99 
Grafiado en colores y con un fondo elíptico con oval de flores se enumera cada parte de la mina y se representa la escala numérica con un compás. Se dispone de una rosa de los vientos dibujada con trazos geométricos.

El plano titulado "De la Quadra de San Lucas de Atalaya y Quadra de Santa Anita, con la Boca de San Vicente, Pozo de San Antonio y San José" (fig.10), firmado por Lázaro Zerrato y Nicolás Esteban Zerrato representa ambas cuadras.

Figura 10. Quadra de San Lucas de Atalaya y quadra de Santa Anita, con la boca de San Vicente, Pozo de San Antonio y San José en el Real de Guanajuato. (1749)

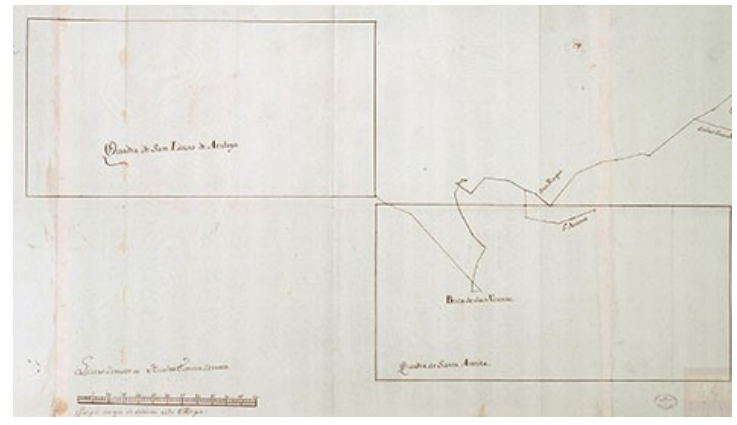

Fuente: Autores, Lázaro Zerrato y Nicolás Zerrato. Archivo General de Indias-Sevilla.

Referencia: MP-México, 103

Y finalmente el titulado "Mapa y tabla geographica de las medidas de las minas nombradas Mellado, Saucedo y Quebradilla, en el Real de Guanajuato, sus bocas, puestos, y labores "(fig.11), donde en la esquina superior izquierda se lee textualmente su título y añade: “...en cuyo conocimiento se vendrá por los números de su correspondencia. Advirtiéndose que las letras del abecedario de las cuatros esquinas de las tres minas son las que terminan sus cuadras de cada una como va figurando". El pitipié de varas dispone de medidas de 10 a 120 varas y en su banda inferior se indica el desglose de letras y referencias. El plano es cromático y por varias veces se representan rosas de los vientos de manera simple y con marcación de los grados en que se disponen los caminos y acequias. También es curioso como en este plano se marca lo "hundido" que se está laborando.
Figura 11. Mapa y tabla geographica de las medidas de las minas nombradas Mellado, Saucedo y Quebradilla, en el Real de Guanajuato, sus bocas, puestos, y labores. (1749)

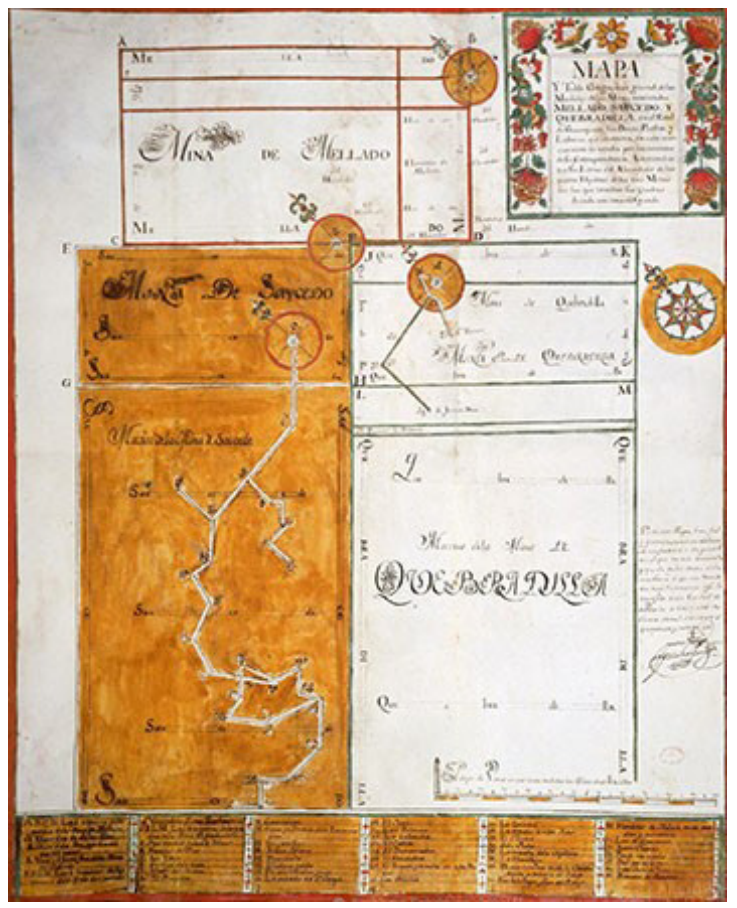

Fuente: Autor, copia realizada por José de Zarazúa. Archivo General de Indias-Sevilla.

Referencia: MP-México, 102

De 1767 es el plano denominado: "Croquis de Guanajuato" (fig.12) que forma parte de un escrito en el que se relatan los alborotos originados en Guanajuato por la expulsión de la Compañía de Jesús. Se representan los asentamientos que rodean al núcleo principal especificando no sólo su localización exacta sino la población que dispone. Parte del asentamiento de Marfil y en sentido antireloj aparecen referenciados: Santa Ana, Cabras, Llanitos, Rosa, Garita, Peregrina, Villalpando, Cubo, Santa Bárbara, San Bruno, Bufa, Solano, Yerbabuena y Santa Teresa. Igualmente está representado el núcleo central de Guanajuato en el que se observan las calles, las iglesias y lo que pueden ser los patios de las haciendas de beneficio. 
Figura 12. Croquis de Guanajuato, situación y bloqueo (1767)

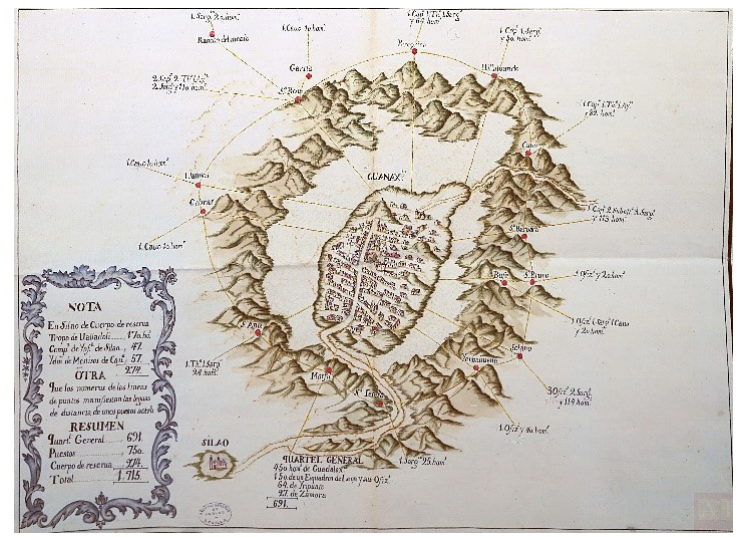

Fuente: Autor desconocido. Archivo General de Indias-Sevilla. Referencia: MP-México, 687

En 1770 se traza el "Mapa de la Intendencia de Guanajuato" (fig. 13) donde se localizan las poblaciones, hidrografía y relieve. Según los archiveros forma parte de la documentación remitida por el virrey Antonio María de Bucareli en carta $\mathrm{n}^{\circ} 1330$, en respuesta a la Real Orden de 15 abril de 1772, sobre el establecimiento de Intendencias en Nueva España.

Figura 13. Mapa de la intendencia de Guanajuato (1770)

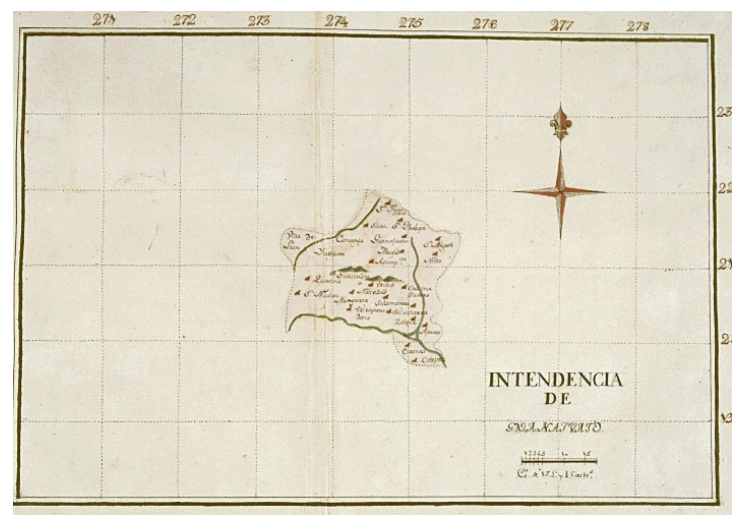

Fuente: Autor desconocido. Archivo General de Indias-Sevilla. Referencia: MP-México, 263

Un último plano referente al territorio y minas es el titulado "Mapa geográfico del obispado de Mechoacán, hecho por el manuscrito de D. Manuel Ignacio Carranza, el de D. José Antonio de Alzate y Ramírez, y otros documentos" (fig.14). El citado obispado abarca Michoacán, Colima, Guanajuato, San Luis Potosí, el límite sur de Tamaulipas y una parte de los estados de Jalisco,
Guerrero y Querétaro. En el plano aparecen grafiadas las ciudades arzobispales, obispales y particulares, además de las villas. También hace distinción entre pueblos españoles, pueblos con parroquia y cura, y pueblos pequeños, pero lo más importante es la localización de haciendas de ganado, haciendas agrícolas, reales de mina y minas de cobre y estaño. En el borde inferior se grafían varias escalas.

Figura 14. Mapa geográfico del Obispado de Mechoacán (1801)

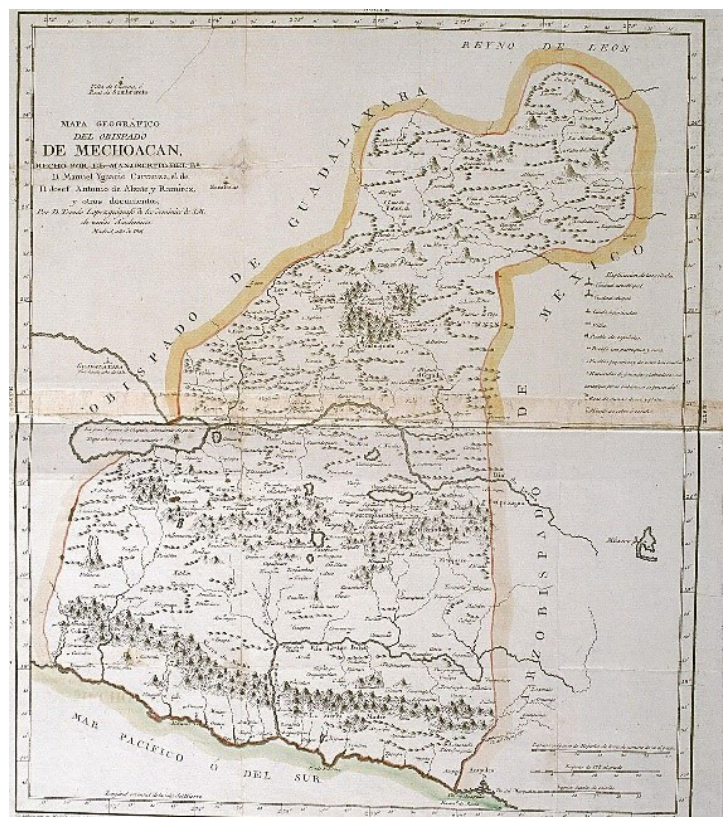

Fuente: Autor, Tomás López. Archivo General de Indias-Sevilla. Referencia: MP-México, 483

Para concluir con la localización de planos referentes a la huella minera en Guanajuato y ubicados en el Archivo de Indias de la capital hispalense, hay archivados dos modelos de viviendas autóctonas tradicionales prácticamente iguales a diferencia de algunos trazados internos: Fechada la denominada "Vivienda de los Altos" en 1783 (Fig.15) y "Vivienda de los Bajos" en 1786 (fig. 16), aunque en el catálogo general del archivo de Indias aparecen ambas catalogadas erróneamente como viviendas en los Altos quizás por la similitud del trazado. En ambos esquemas pueden observarse las piezas que conforman las haciendas y la parte de las mismas destinadas al beneficio del mineral (patios de ensaye). 
Figura 15. Casas del Real ensaye de Guanajuato; vivienda de los altos (1783)

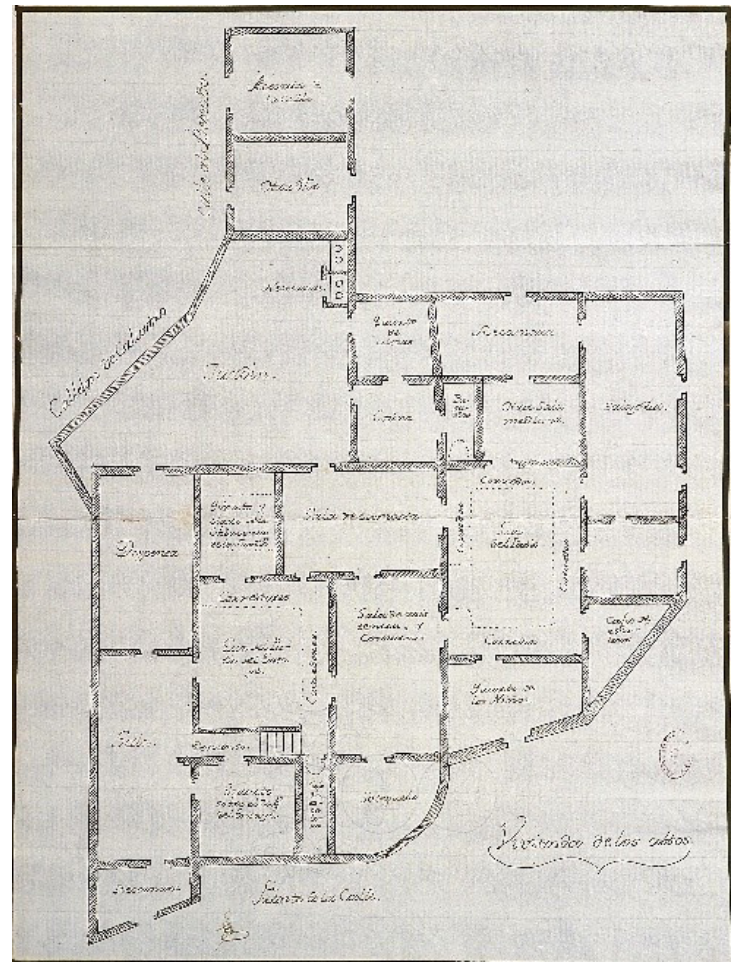

Fuente: Autor desconocido. Archivo General de Indias-Sevilla. Referencia: MP-México, 676

Figura 16. Casas del Real ensaye de Guanajuato; vivienda de los bajos (1786)

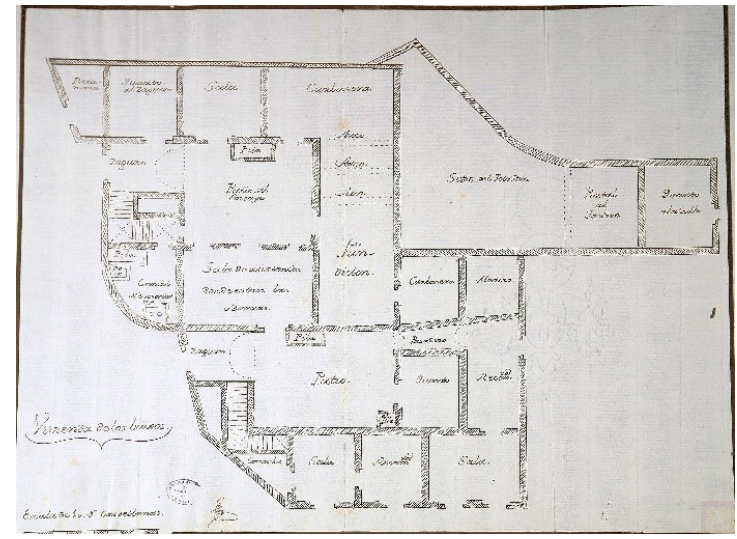

Fuente: Autor desconocido. Archivo General de Indias-Sevilla. Referencia: MP-México, 675

\section{PRODUCCIÓN Y HACIENDAS DE BENEFICIO}

\section{Sistemas de producción}

En 1548 los españoles inician la actividad minera con el sistema de extracción denominado de lumbreras, calentando y enfriando las rocas rápidamente puesto que tanto el oro como la plata están superficiales. Para el beneficio del mineral usan el método de fundición con el que llega a obtenerse la cuarta parte de la plata extraída en Guanajuato. Posteriormente en 1556 ante la disminución del rendimiento, tanto por el desgaste de la riqueza mineralógica del suelo como por el cambio de las nuevas leyes que no permiten la esclavitud convirtiéndose los mineros y esclavos en asalariados, un español usa para el beneficio del mineral el método alemán de la amalgamación de plata con el sistema de patio, usando sal, agua, sulfato de cobre y mercurio en frio, de modo que extrae plata y oro conjuntamente y posteriormente separa ambos minerales con ácido sulfúrico en la casa de la moneda. Este método usado hasta 1905 produce las tres quintas partes de plata del mundo hasta inicios del siglo XX. Los daños medioambientales de la época son notables: extraer los dos metales preciosos y acopiar la ganga en los cauces de agua que discurren bajo las haciendas de beneficio, la existencia y localización en el territorio de haciendas de beneficio sin ningún tipo de planificación urbanística, arrojar el mercurio utilizado para el proceso de amalgamación, una vez utilizado, al suelo y a los cauces de agua directamente entre otros, nos da la imagen de un paisaje único.

Desde 1726 se usa también el sistema de extracción con dinamita permitiendo la obtención de los metales a mayor profundidad, por ejemplo, en la parte central de la denominada Veta Madre se llegan a profundizar hasta 400 metros lugar donde ya son visibles las corrientes subterráneas de agua. Con la aprobación en 1892 de la Ley Minera y la participación de empresas norteamericanas se introduce la electricidad como fuerza motriz facilitando en gran medida el uso de maquinaría de alta tecnología (Ramos-Prol-Siebe, 2004, p 276).

A inicios del siglo XIX, y usando la dinamita como único sistema de extracción, se pone en práctica el método de cianuración que se implanta de manera gradual en todas las haciendas de beneficio y cuyo residuo de cianuro se vuelve a verter directamente a los cauces de los ríos y posteriormente a las denominadas presas de jales, construidas sin desviar la cuenca y susceptibles de erosión (Ramos-Prol-Siebe, 2004, p 277). Geólogos de prestigio han estudiado la posible contaminación ocasionada por el mercurio y 
cianuro, y aún no existen pruebas concretas de un daño medioambiental irreversible (RamosProl-Siebe, 2004, pp 279-283). Durante la Guerra de la Independencia mexicana las minas son abandonadas y automáticamente se inundan de manera natural, hasta que con la llegada de empresas inglesas en 1825 se consigue desaguar las minas e introducir nuevos sistemas de molienda sustituyendo las poleas con fuerza humana por fuerza animal.

\section{Las Haciendas de Beneficio}

La ciudad de Guanajuato, vistos los métodos de beneficio del mineral, pasa por una serie de transformaciones urbano-territoriales en relación a las diferentes etapas de producción (Ordaz-PuyVidarri, 2007, pp 49-50). En referencia a los lugares en torno a los cuales se desarrolla la manipulación y extracción de plata y oro, destacan las haciendas de beneficio para producir las barras de oro y plata como instalaciones industriales del momento, aunque no hay que olvidar de la existencia de haciendas mineras para la extracción de mineral. Las primeras instalaciones mineras, precursoras de las conocidas haciendas de beneficio, tienen su origen en el siglo XVI, y puesto que necesitan de una fuente de abastecimiento de agua para el manejo del mineral es lógico que se ubiquen en sus inicios en las laderas de las cañadas y próximas a ríos y arroyos (Ordaz-Puy-Vidarri, 2007, pp 5152), escogiendo aquellos lugares donde se prevé la bonanza minera y que coincide con el futuro núcleo urbano de la ciudad de Guanajuato. Esta casuística genera una traza territorial irregular y difícil de comprender que se incrementa a partir de 1558 cuando los propios mineros una vez vista la producción inicial, prefieren adquirir propiedades para sus instalaciones en la zona de la cañada antes que seguir haciéndolo dentro del propio núcleo urbano (Ordaz, 2015, pp 49-59).

Las instalaciones localizadas en el interior del núcleo urbano pasarán a denominarse haciendas de beneficio, pues reciben el mineral en bruto de las explotaciones para el beneficio del mismo, hasta que en el siglo XVIII se trazan en la periferia de la ciudad por colmatación obvia de la traza urbana (Ordaz-Puy-Vidarri, 2007, pp 53-59). El auge de estos edificios surge a raíz de las reformas borbónicas (1765-1808) creándose lo que hoy día se denominaría corredor industrial. Las superficies construidas de estas haciendas varían entre las más pequeñas localizadas en el núcleo urbano, y que son las que más transformaciones por antigüedad han sufrido, y las de un tamaño considerable localizadas en la periferia urbana pues como se ha comentado con anterioridad, en estas haciendas no sólo se beneficia el mineral, sino que también se dispone de pequeños huertos y establos para alimentar a los trabajadores. Entre 1686 y 1740 Guanajuato cuenta con 64 haciendas de beneficio trabajadas por 208 beneficiadores (Torres, $2001, \mathrm{~s} / \mathrm{p}$ ). Las haciendas grandes con el tiempo se fraccionan para separar a los grupos de trabajadores, indios y negros, en las denominadas cuadrillas, llegándose a convertir en alguno de los barrios que configuran la actual ciudad de Guanajuato.

En lo que al beneficio de minerales se refiere, las haciendas albergan dentro sus extensiones territoriales varios elementos arquitectónicos construidos exprofeso para cada uno de los pasos que debe seguir el beneficio por amalgamación, además tienen una estructura espacial diferente en función de su localización (Ordaz, 2015, pp 59). Los aportes descriptivos y bocetos realizados por Henry George Ward y su esposa en el libro titulado México en 1827, y las realizadas por Friedrich Sonneschmid, un minero con formación en estudios mineralógicos, sobre las haciendas de beneficio localizadas en la propia ciudad de Guanajuato, son las principales fuentes de que se dispone. En general la hacienda está construida con materiales del entorno, mampostería y sillería.

En las haciendas de beneficio se realiza el complejo proceso de amalgamación, el cual necesita de una serie de espacios específicos desde la salida del mineral de la mina hasta su transformación en lingotes. Antes de llegar al patio, elemento principal en torno al cual se genera la vida minera, se localizan: la galería de selección, que suele ser un habitáculo al aire libre, aunque tiene parte techada, con el fin de recepcionar el mineral y separar de forma manual lo inservible, y la galería de molienda con cinco metros de altura y a veces hermosos arcos de adobe y techado donde se ubican los llamados molinos de pisones y los de arrastres o tahonas que requerían de grandes galeras techadas. A continuación, y en una especie de conducto se incorpora mercurio, agua y se hace la torta de mineral (Gómez, 2005, p 86).

La siguiente pieza es el patio, un lugar abierto, embaldosado y con cierta pendiente para escurrir el agua y donde se suelen echar los productos químicos como el sulfato de cobre, mercurio 
y agua. El tamaño de la superficie es variable existiendo en Guanajuato haciendas de beneficio que tienen cabida en sus patios de 30 a 40 cúmulos de mineral de entre 15 y 33 quintales frente a otras que llegan hasta 300 cúmulos. Las haciendas con patios más pequeños suelen ser las ubicadas en el centro urbano por cuestiones lógicas del espacio (hoy convertidas en espacios y plazas públicas), y las más grandes las ubicadas en la periferia (Gómez, 2005, p 102). Con el patio se comunica la galería de lavado que dispone, en una superficie regular, las tinas de lavado donde se separa el lodo del mineral gracias al movimiento de aspas con tracción animal, y a la que le acompaña la construcción del abastecimiento y retirada de agua. A continuación, se ubica la sala de ensaye que tiene varias funciones siendo un espacio pequeño y techado. Finalmente el horno, un espacio de unos tres metros de altura y techado, a excepción de la zona del tiro de las chimeneas, donde se realiza la última etapa y la fundición de la plata en barras (Gómez, 2005, p 103).

Para guardar las herramientas, utilizadas tanto en el trabajo manual como en la fragua, se construyen edificios y almacenes anexos como por ejemplo la carbonera o la azoguería, o para guardar el grano que alimenta a los trabajadores se construye el troje. También los espacios para uso animal son importantes como el corral para los caballos o el establo para las vacas. Por supuesto no se pueden olvidar los espacios destinados a la residencia pues realmente estamos ante una hacienda (ver figuras 15 y 16) : la casa principal, con patio trasero en el que hay un huerto, construida frente al patio desde donde se domina prácticamente todo el circuito; la casa del mayordomo, responsable de la hacienda y del proceso del beneficio, trazada con una pequeña sala, dormitorio y cocina; y los habitáculos construidos con materiales poco estables donde permanecen los esclavos negros fuertemente custodiados (Dávila, 2007, pp 52-56) .

Para los operarios (indígenas libres e indígenas forzados)quetrabajabanenelbeneficioy comerciantes (blancos o mestizos) se construyen viviendas simples con materiales pobres, normalmente de adobe y de una sola planta con una habitación grande (el salón), otra más pequeña (el dormitorio), además de cocina, bodega, y a veces pozo, corral y establo. Para operarios más especializados las viviendas son de piedra y dos plantas con más habitaciones y espacios comunes.

\section{MORFOLOGÍA URBANA A TRAVÉS DE LA PLANIMETRÍA}

Desde que en 1554 se funda el asentamiento de Guanajuato y se fundan las primeras instalaciones industriales, antecedentes de las primeras haciendas de beneficio de oro y plata que hasta ese momento tienen uso agrícola, son frecuentes los asentamientos dispersos y secundarios que originan asentamientos poblacionales estables y que son los precursores de los diferentes barrios de la futura ciudad que cuenta ya con un total de algo más de 4.000 habitantes. En 1558 con el trabajo en la Veta Madre se genera la proyección de verdaderos poblados y campamentos-fortines como los de Santiago (de Marfil), Tepetapa, Santa Ana y Santa $\mathrm{Fe}$, considerándose éste último el principal (figura 01), mientras se construyen en estos poblados alojamientos para las cuadrillas de mineros, iglesias y hospitales independientes para los trabajadores de las minas, indios otomíes, tarascos, mexicanos y mazahuas que mantienen una marcada segregación social entre ellos. Desde que el fortín de Santa Fe adquiere el título de Villa en 1619, el parcelario se traza de manera que se eviten deslizamientos del terreno debido a las escorrentías de agua y siempre en paralelo a los cursos de agua, y los fortines, que han perdido su carácter militar, se transforman en poblados que al igual que los asentamientos mineros se localizan en lugares aislados y crecen de forma espontánea. Tan sólo los espacios dedicados al culto religioso adquieren un papel significativo y determinan el lugar donde posteriormente se erigirán las iglesias.

Por otro lado, el hecho de que, durante los siglos XVII-XVIII, las minas cambien de propietario y ubicación constantemente en busca de un mayor rendimiento, provoca el aumento del número de excavaciones y haciendas de beneficio (figura 07), que a su vez se dividen en porciones más pequeñas para ser explotadas de modo familiar. Esta peculiaridad hace que debido al sistema de patio para el beneficio del mineral se duplique el número de patios y a la larga genere un mayor número de espacios libres en la ciudad de Guanajuato al desaparecer el uso minero. Ya reconocida Guanajuato como ciudad en 1741, el crecimiento continúa siendo mucho más intenso y continua por ambas márgenes del río, de modo que la mitad de la ciudad está ocupada por edificios religiosos y la otra por haciendas de beneficio. $\mathrm{La}$ 
inundación de 1760 afecta de tal forma al núcleo urbano que se proyectan muros para encajonar el rio a su paso por la ciudad, mientras en su periferia los asentamientos industriales desligados del centro urbano crecen alrededor de la iglesia adaptándose a las condiciones físicas del terreno.

A partir de 1768 y gracias a la actividad minera (figuras 04-07-09-10-11) y al descubrimiento de la mina Valenciana, localizada entre Mellado y Rayas (figuras 02-03-06) dentro del área de la Veta Madre, la ciudad de Guanajuato se convierte en la más floreciente de Nueva España (Blanco-Parra-Ruiz, 2016，s/p) y comienza a densificarse, necesitando el núcleo principal una infraestructura potente de abastecimiento de agua y el adoquinado de sus calles más importantes.

En 1770 se realiza el mapa de la intendencia de Guanajuato (figura 13), y en 1780 se estima que la ciudad cuenta con 50 haciendas de beneficio de tamaño grande-mediano y unas 300 de menor tamaño que no son sino casetones (figura 05) (Brading, 2015, s/p). En referencia a la configuración urbana del núcleo principal de Guanajuato ésta es deficiente contando con pocas calles demasiado tortuosas (figura 12), en esta situación la población vive prácticamente en chozas localizadas en los cerros que se ocupan y desocupan con los avances mineros. Convertida ya en capital (figura 14) de una de las doce provincias de México desde 1786, Guanajuato cuenta con una población de 55.000 personas que representan el $10 \%$ de la población total de Nueva España necesitando la misma obras de carácter general: encauzamiento de los arroyos, reemplazo de los puentes de madera por piedra, elevación de algunos puntos de la ciudad sacrificando muchos de los edificios barrocos, y consolidación del pavimento con adoquines en las calles que aún eran de tierra. Como proceso lógico de crecimiento, comienzan a conurbarse los núcleos dispersos existentes y a reutilizarse las porciones de tierras de las haciendas que no se destinan para uso agrícola con fines mineros.

$\mathrm{Al}$ iniciarse la Guerra de Independencia en 1810 la ciudad tiene censados cerca de 90.000 habitantes y está sometida a una serie de irregularidades: desagua sus desechos al cauce del río así como los excedentes mineros de las haciendas de beneficio, las edificaciones están en mal estado y parte de ellas son afectadas por los acontecimientos, se han de construir fortificaciones de defensa en los accesos y periferia, se produce el abandono de algunos asentamientos mineros por la inutilización de las propias minas, e incluso algunos edificios religiosos, señas de identidad de los pobladores, son demolidos.

En torno a 1825 se establecen en la ciudad empresas inglesas que se hacen con la extracción de mineral, pero los problemas con que se encuentran son graves: el consumo indiscriminado de madera para el apeo de las galerías mineras, la obtención de leña como combustible para el desgaje de las rocas por calentamiento, o el consumo doméstico han convertido a la sierra en un erial que incrementa las posibilidades de inundación y escorrentías mal dirigidas, y la desforestación es de tanto alcance que ni siquiera sirve para dar continuidad en el servicio a las máquinas de vapor inglesas que laboran en Guanajuato.

Al mismo tiempo que se realizan importantes obras de infraestructuras relacionadas con la movilidad, continúan los encauzamientos subterráneos, se incorporan nuevas trazas para el ferrocarril y tranvía urbano, e incluso en 1827 se dota a la ciudad de alumbrado y en 1851 se equipa la ciudad con un servicio de aseo-baño de carácter de uso público. Llegado el año 1886 las inundaciones de la ciudad continúan y es necesario buscar una solución: la ciudad prácticamente se reconstruye subiéndole el nivel (Trujillo, 2015, pp 8-14) y se quedan soterradas construcciones enteras.

El siglo XIX finaliza con la reestructuración de la ciudad y la mejora de los caminos que unen el núcleo urbano con los poblados y cuyo límite son las haciendas de beneficio, en este sentido la ley sobre Ocupación y Enajenación de Terrenos Baldíos del 1894 es uno de los desencadenantes de la revolución mexicana (Guzmán, 2005). Paralelamente el ralentizamiento de la actividad minera y el abandono de las haciendas de beneficio dan lugar a la configuración actual de la ciudad de Guanajuato que durante el siglo XX y XXI ofrece un crecimiento sin igual, llegando a contar con una población de 184.239 habitantes censados en 2015.

\section{CONCLUSIONES. HUELLA DE LA MINERÍA EN EL SIGLO XX}

El inicio de la Revolución Mexicana en 1910 supone un inciso en la evolución económicosocial de la ciudad de Guanajuato, produciendo importantes reformas para el pueblo mexicano 
y revalorando el Ejido como una célula política y económica. En 1921 el censo general de habitantes de Guanajuato publica 19.408 habitantes lo que indica una clara progresión en alza. Durante todo este siglo la ciudad de Guanajuato continúa colmatándose: se inaugura en 1964 la denominada Calle Subterránea sobre una antigua cañada que cuenta con una longitud de 2,9 kilómetros, y ante los efectos de mejoras en salubridad y movilidad se ejecutan otros túneles para una ciudad que cuenta ya con 65.324 habitantes. Desde este momento la ciudad perderá su carácter minero y artesanal desarrollándose una interesante actividad turística apoyada por la construcción de la Carretera Panorámica en 1973 que rodea a toda la ciudad proporcionando unas vistas espectaculares sobre el interesante paisaje.

En julio de 1982 la ciudad es declarada Zona de Monumentos Históricos por el Instituto de Antropología e Historia. De los 831 Monumentos Históricos Catalogados sólo están reconocidos 552 y desde 1993 se aumenta a 639. Además en 1988 fue inscrita por la UNESCO en la Lista de Patrimonio Mundial bajo el nombre de Ciudad Histórica de Guanajuato y Minas Adyacentes con un área protegida de 2.264 hectáreas de las cuales sólo 1.200 hectáreas se encuentran edificadas. En 2006 tiene el reconocimiento de ser la Quinta Ciudad más Bella del Mundo, reconocimiento realizado por National Geographic. En el año 2015 y tras casi quinientos años de existencia, la ciudad de Guanajuato cuenta con 184.239 habitantes (Ruíz, 2012, pp 149-150). C

\section{REFERENCIAS BIBLIOGRÁFICAS}

Antúnez, Francisco (1964). Monografia histórica y minera sobre el Distrito de Guanajuato. Capítulo, p 588. Ciudad de México (México). Editorial Consejo de Recursos Naturales no Renovables.

Blanco, Mónica. - Parra, Alma. - Ruiz, Ethelia. (2016-ePub). Historia breve de Guanajuato. Ciudad de México (México). Editorial Fondo de Cultura Económica.

Brading, David (2015-ePub). Mineros y comerciantes en el México borbónico (1763-1810). Traducción Gómez Ciria (1975). Ciudad de México (México). Editorial Fondo de Cultura Económica.

Dávila, Gerardo (2007). Guanajuato (México): La transformación Urbana de una Ciudad
Minera del siglo XVI. Capítulo 3, pp 4146 y 52-56. Capítulo 4, pp 77-78. Sevilla (España). Editorial Trabajo Suficiencia Investigadora Doctorado Universidad de Sevilla.

Gómez, Oriel (2005). El beneficio por cianuración en Guanajuato, hacia el análisis sociotécnico. Capítulo 1, pp 77105. Michoacán (México). Editorial Tesis Doctoral Universidad de Michoacán de la Universidad de Michoacán de San Nicolás de Hidalgo.

Guzmán, Edgar A. (2016). Modos de crecimiento urbano de la ciudad de Guanajuato (15542015). Estudio y aplicación de métodos cartográficos digitales. Planimetrías 25 , 26, 36, 69, 76, 156-164, pp 56, 59, 65, $85,92,121,125,128,131,136,139,142$, 146, 148. Guanajuato (México). Editorial Trabajo Fin de Licenciatura Universidad de Guanajuato.

Hausberger, Bernd (1995). "La minería novohispana vista por los "libros de carga y data" de la Real Hacienda (1761-1767)". Estudios de historias novohispanas. Número 15, pp 32-64. Ciudad de México (México). Editorial Estudios Historia Novohispana de la Universidad Nacional de México.

Manso, Carmen (2008). "La colección cartográfica de América de Alexander von Humboldt conservada en la Real Academia de la Historia". Boletín de la Real Academia de la Historia. Tomo CCV. Cuaderno III, pp 537-589. Madrid (España). Editorial Real Academia de la Historia.

Torres, Eugenio (2001). El beneficio de la plata en Guanajuato, 1686-1740. Guanajuato (México). Editorial Presidencia Municipal de Guanajuato.

Ordaz, Velia Y - Puy, María Jesús - Vidaurri, Eduardo (2007 e-Pub). "Conservación urbana en sitios históricos, ¿una utopía? El caso de la ciudad de Guanajuato, México". Arquitectura y Ciudad. Habitabilidad en Guanajuato. Tomo 1,pp 49-59. Guanajuato (México). Editorial Ide@s Concyteg.

Ordaz, Velia Y. (2015). "Nuevos usos del patrimonio en una ciudad histórica". Encuentro Internacional Usos del Patrimonio: Nuevos Escenarios. Mesa II Valores Identidades Patrimoniales, pp 
49-59. Guanajuato (México). Editorial Instituto Nacional de Antropología e Historia de México.

Ramos, Yann R. - Prol, Rosa M - Siebe, Christina (2004). "Características geológicas y mineralógicas e historia de extracción del Distrito de Guanajuato, México. Posibles escenarios geoquímicos para los residuos mineros". Revista Mexicana de Ciencias Geológicas, volumen 21, pp 268-284. Querétaro (México). Editorial Instituto Geología de la Universidad Nacional Autónoma de México.

Ruiz, Agustín (2012). Guanajuato (México): dinámica y estructura de un destino turístico patrimonio de la humanidad. Capítulo 2, pp 92-126. Capítulo 3, 149155. Madrid (España). Tesis Doctoral Universidad Complutense de Madrid.

Staples, Anne (2018-ePub). "Los intereses británicos en la minería mexicana: una mirada historiográfica”. Diplomacia, negocios y política. Ensayos sobre la relación entre México y el Reino Unido en el siglo XIX. Número de 2018, pp 79-102. Ciudad de México (México). Editorial Instituto de Investigaciones Históricas de la Universidad Nacional Autónoma de México.

Trujillo, Alfredo (2015-ePub). "Primer contacto con el Río Guanajuato. Origen de las construcciones. Calle Subterránea Miguel Hidalgo. Crónica de la Urbanización del Río Guanajuato. Apartados 2-3, pp 8-14. Guanajuato (México). Editorial Project Gutenberg Self-Publishing Press y el autor.

Uribe, José A (2001). "Economía y mercado en la minería tradicional mexicana, 1872-1929". Revista de Indias. Volumen LXI, número 222, pp 267-290. Michoacán (México). Editorial Instituto Investigaciones Históricas de la Universidad de Michoacán de San Nicolás de Hidalgo.

Villalba, Margarita (2013). "Trabajo en las minas de Guanajuato durante la segunda mitad del siglo XVIII". Estudios de historias novohispanas. Número 48, pp 35-83. Ciudad de México (México). Editorial Estudios Historia Novohispana de la Universidad Nacional Autónoma de México.

Zamora, Verónica (2004). “Asentamientos Prehispánicos en el Estado de
Guanajuato". Acta Universitaria de la Facultad de Arquitectura de la Universidad de Guanajuato. Volumen 13. Número 2, pp 25-44. Guanajuato (México). Editorial Universidad de Guanajuato 